\title{
Structure of the $5^{\prime}$ untranslated regulatory region of ferritin mRNA studied in solution
}

\author{
Yuh-Hwa Wang ${ }^{\star}$, Stephen R.Sczekan ${ }^{+}$and Elizabeth C.Theil \\ Department of Biochemistry, North Carolina State University, Raleigh, NC 27695-7622, USA
}

Received April 23, 1990; Revised and Accepted June 20, 1990

\begin{abstract}
Ferritin mRNAs are the first eukaryotic mRNAs for which a conserved, translational regulatory sequence has been identified. The sequence of twenty-eight nucleotides, called the IRE (iron regulatory element), is found in the $5^{\prime}$-noncoding region and is required for enhanced translation of ferritin mRNA by excess cellular iron; regulation occurs at initiation. The prediction of secondary structure in the IRE is a hairpin loop. We now report an analysis of the IRE structure in solution studied in natural ferritin mRNAs [H and $H^{\prime}(M)$ subunits] by primer extension, after modification or cleavage by dimethyl sulfate, RNAases $T_{1}$ and $V_{1}$, and the chemical nuclease 1,10-phenanthroline-copper (OPCu) which cleaves single-stranded and bulged regions of RNA. Overall, the structure in solution of the ferritin mRNA regulatory region is a hairpin loop, with magnesium-sensitive features, in which half the stem is provided by the IRE and half by flanking regions; only secondary structure is conserved in the flanking regions. Predicted bulges or internal loops along the stem were clearly detected by OPCu but were missed by the more bulky probe RNAase $T_{1}$, indicating the efficacy of OPCu in probing subtle features of RNA structure. Magnesium-dependent deviations from the predicted structure were observed in the stem between the hairpin loop and the bulge at $C^{6}$. The location of the IRE in relation to the initiator AUG or the cap is variable in different ferritin mRNAs. However, the number of nucleotides in the base-paired flanking regions of known ferritin mRNAs is proportional to the distance of the IRE from the cap and places the secondary/tertiary structure 8-10 nucleotides from the cap where interference with initiation is likely.
\end{abstract}

\section{INTRODUCTION}

Ferritin synthesis has become a paradigm for translational regulation $(1,2)$. Translational regulation is demonstrated by the observation that 30-50x increases in ferritin synthesis occur with no change in ferritin mRNA concentrations when cellular iron levels increase $(3,4,5,6)$. [Since the biological role of ferritin is to store large amounts of iron, in an inorganic core, control of ferritin synthesis by iron is a form of autogenous regulation.] The site of translational control of ferritin synthesis is mainly at initiation (7) with untranslated ferritin mRNA stored in the cytoplasm $(6,8)$. When cellular iron is in excess ferritin mRNA is able to form polyribosomes (8). Ferritin mRNA translation can also be specifically regulated in vitro in reticulocyte lysates (9) which led to the identification and purification of a specific ferritin mRNA regulator protein $(10,11)$. The prediction of specific mRNA-protein complexes to regulate protein synthesis in eukaryotes made twenty years ago (12) has now been fulfilled with ferritin mRNA.

What are the specific features of ferritin mRNA required for translational control? Comparison of the eight different ferritin mRNA sequences currently available, representing mammals, birds and amphibia, shows a highly conserved sequence of 28 nucleotides, 16-38 nucleotides from the cap (2) which was originally noted by Leibold and Munro in 1986. Transfection studies in whole cells have amply demonstrated the requirement of the conserved sequence for the regulation of ferritin synthesis by iron (as added hemin) (13-20). Moreover, a ferritin mRNA translational regulator protein binds to the conserved ferritin mRNA sequence $(10,21)$. A protein of a size similar to the regulator protein has been identified in cell extracts by retardation of oligoribonucleotides during gel electrophoresis $(17,22)$ and purified using the conserved sequence as a specific ligand (20). Sequences in the $3^{\prime}$-untranslated region of ferritin mRNA also contribute to the translational regulation of ferritin synthesis $(9,14)$, but sequence conservation in the $3^{\prime}$-untranslated region has not been detected; however, predicted secondary structures appear to be conserved (9).

Neither the IRE structure nor the flanking regions of ferritin mRNAs have been examined except by sequence comparison and secondary structure predictions. The IRE regulatory region is predicted to form a stem consisting of ten highly conserved nucleotide pairs from flanking regions. The hairpin loop consists of six nucleotides, CAGUGU/C (Figure 1).

We now report studies of the structure in solution of both the IRE and flanking regions in ferritin mRNA using chemical modification, and both enzymatic and chemical cleavage to probe accessible single and double stranded regions. Ferritin mRNA

Present addresses: * Department of Microbiology and Immunology, The Lineberger Cancer Research Center, University of North Carolina at Chapel Hill, Chapel, NC 27514 and + Department of Cellular and Developmental Biology, Harvard University, Cambridge, MA 02138, USA 
was analyzed in polyA ${ }^{+}$RNA by primer extension. The results show that many of the bases in the IRE and flanking regions that are predicted to be paired are indeed inaccessible to probes of unpaired bases. In addition, sites of cleavage of ferritin mRNA by 1,10 -phenanthroline- $\mathrm{Cu}(\mathrm{OPCu})$, a probe for single strands or loops in RNA (26), were strikingly sensitive to changes in magnesium concentration. At $0.5 \mathrm{mM}$, even some nucleotides in the stem at the base of the hairpin loop were cleaved, showing the existence of different conformers of the IRE. The combination of the IRE and the base-paired flanking sequence places the secondary/tertiary structure of the regulatory region within ten nucleotides of the cap providing a possible explanation for interference with initiation of translation.

\section{EXPERIMENTAL PROCEDURES}

\section{RNA}

PolyA $^{+}$RNA was isolated from reticulocytes of bullfrog tadpoles (Rana catesbeiana) as previously described (3). In vitro transcripts (IVT) of the $\mathrm{H}^{\prime}(\mathrm{M})$ ferritin subunit Rana catesbeiana pseudogene were prepared as previously described (9); the three lengths of $3^{\prime}$-untranslated region tested were 24 and 94 nucleotides and full length.

\section{Cleavage or Modification Reactions}

The results of cleavage or modification were analyzed by primer extension. Specific primers which bound 15 or 23 nucleotides downstream from the ferritin mRNA regulatory region $[\mathrm{H}$ or $\mathrm{H}^{\prime}(\mathrm{M})$ subunit mRNA] were used to examine mRNA modification or cleavage in polyA ${ }^{+}$or IVT. Primer binding, incubation with reverse transcriptase and separation of DNA

Table I. Major Modification or Cleavage Sites in the Regulatory Region of the 5'-Noncoding Segment of Ferritin mRNA (H subunit) from Bullfrog Red Cells ${ }^{a}$

\begin{tabular}{lllll}
\hline Reagent & $\mathrm{A}^{\mathrm{b}}$ & $\mathrm{C}^{\mathrm{b}}$ & $\mathrm{G}^{\mathrm{b}}$ & $\mathrm{U}^{\mathrm{b}}$ \\
\hline DMS $^{\mathrm{c}}$ & $13,16^{\mathrm{e}}, 21,22$ & $6,41,46,48$ & - & - \\
RNAase $^{\mathrm{T}} \mathrm{T}_{1}$ & & - & 14,45 & - \\
OPCu $^{\mathrm{c} d}$ & - & 32 & $5,14,16$, & $8,15,18,19,35$ \\
RNAase $\mathrm{V}_{1}$ & 37 & - & $20,24,25,36$ & \\
\end{tabular}

a The base composition of the conserved sequence and flanking sequences is pyrimidine rich: $A_{15}, C_{20}, G_{13}, U_{25}(P y r / P u=45 / 28)$. Similar results were obtained probing native $H^{\prime}(M)$ ferritin subunit mRNA (Figure 2 ) and pseudogene IVT and a 55 mer containing the IRE and blanking regions (data not shown). b The conserved regulatory sequence is numbered 1 to 28 starting at the $5^{\prime}$ end; in this scheme initiation of translation begins at 149 and the cap is at -23 . DMS = dimethyl sulfate (data not shown) - only modified $\mathrm{A}$ or $\mathrm{C}$ can be detected by primer extension (33); $\mathrm{OPCu}=1,10$-phenanthroline $\mathrm{Cu}(30){ }^{\mathrm{d}}$ Accessibility to $\mathrm{OPCu}$ was affected by varying the concentration of $\mathrm{Mg}$. For example, $\mathrm{G}^{14}$, $\mathrm{U}^{15}, \mathrm{G}^{16}, \mathrm{U}^{18}$, and $\mathrm{U}^{19}$ were not cleaved at 0 or $5 \mathrm{mM} \mathrm{Mg}$ but were cleaved at $0.5 \mathrm{mM} \mathrm{Mg}$. The affect of $\mathrm{Mg}$ is less marked in the in vitro transcript of the $\mathrm{H}^{\prime}(\mathrm{M})$ subunit pseudogene. ${ }^{\mathrm{e}}$ In the transcript of the pseudogene only which has a $\mathbf{G} \rightarrow \mathrm{A}$ substitution at position 16 .

Native ferritin mRNA, in polyA + RNA naturally rich in ferritin mRNA (10\%) was treated with cleavage or modifying reagents in $25 \mathrm{mM}$ Hepes. $\mathrm{Na}, \mathrm{pH}=7.2$, with $40 \mathrm{mM} \mathrm{KCl}$ at $30^{\circ}(\mathrm{Mg}$ : 0 and $0.1 \mathrm{mM}$ for RNAases and $0-5 \mathrm{mM}$ for $\mathrm{OPCu}$ and DMS) and analyzed by primer extension (see Materials and Methods). The results were obtained from 3-5 experiments. DMS and OPCU were used with both $\mathrm{H}$ and $\mathrm{H}^{\prime}(\mathrm{M})$ ferritin subunits and IVTs of a $\mathrm{H}^{\prime}(\mathrm{M})$ subunit pseudogene (25) with similar results except that positions 21 and 22 were moderate DMS sites in the $H^{\prime}(\mathrm{M})$ subunit $\mathrm{mRNA}$ and the A substitution at position 15 in the IVTs was a strong DMS site. The results indicate a hairpin loop, with several magnesium-sensitive regions near bulges, loops, and the base of the hairpin loop, that is composed both of the conserved IRE and the flanking sequences. Possible secondary/tertiary interactions involve bases in the hairpin loop based on the differential accessibility of $\mathrm{G}$ residues to OPCu and RNAase. fragments by electrophoresis in acrylamide gels followed procedures previously used (6).

All cleavage or methylation reactions were carried out at $30^{\circ} \mathrm{C}$ in $25 \mathrm{mM}$ Hepes $\cdot \mathrm{Na}$ (Boehringer-Mannheim), $\mathrm{pH}=7.2,40 \mathrm{mM}$ $\mathrm{K}$ acetate and varying concentrations of $\mathrm{MgCl}_{2}$, and were adjusted to assure less than one modification or cleavage event per RNA molecule. The use of $80 \mathrm{mM} \mathrm{K}$ acetate did not change the results. Modified or cleaved RNA was precipitated with alcohol before analysis; enzymes were removed by phenol extraction. $V_{1} R N$ Aase, purchased from Pharmacia, was used at $7 \mathrm{U}$ units $/ \mathrm{ml}$ and $R N$ Aase $\mathrm{T}_{1}$, the product of $\mathrm{BRL}$, was used at $7 \mathrm{U} / \mathrm{ml}$; polyA ${ }^{+}$concentrations were $60-80 \mathrm{microg} / \mathrm{ml}$. Dimethyl sulfate (DMS) was purchased from Aldrich Chemical; 50 microL reaction mixtures $88 \mathrm{mM}$ in DMS and containing 2 or 0.6 microg of poly ${ }^{+}$RNA or IVT, respectively, were incubated with $\mathrm{DMS}$ for $30 \mathrm{~min}$ at $30^{\circ} \mathrm{C}$. Cleavage by 1,10-phenanthroline- $\mathrm{Cu}(\mathrm{OPCu})$ followed the procedure of Yoon et al. (24) with 9 microM Cu, using mercaptopropionic acid to start the reaction (no cleavage occurred with $\mathrm{Cu}$ alone). Five minute reactions were terminated with a 45-fold excess of 2,9-dimethyl-1,10-phenanthroline (24). Concentrations of OPCu up to 45 microM $\mathrm{Cu}$ were tested with no change in the cleavage pattern.

\section{Computer Predictions}

The University of Wisconsin Genetics Computer Group Fold Program, Version 5.0, was used as developed by Zucker and Steigler (23) and Frier et al. (40).

\section{RESULTS}

To study the secondary/tertiary structure of the regulatory sequences in the IRE and flanking sequences of the 5'-untranslated region of ferritin mRNAs, chemical modification and cleavage were carried out under conditions where less than one cleavage or modification occurred/RNA molecule. Native ferritin mRNA was examined in a natural $\mathrm{mRNA}$ mixture using polyA ${ }^{+} \mathrm{mRNA}$ from reticulocytes of the embryonic cell line of bullfrogs where the proportion of ferritin mRNA is ca $10 \%(3,6)$. Both $\mathrm{H}$ and $\mathrm{H}^{\prime}(\mathrm{M})$ ferritin subunit mRNAs (25) were studied as well as in vitro transcripts (IVTs) of a genomic ferritin processed pseudogene; the pseudogene encoded the full length $\mathrm{H}^{\prime}(\mathrm{M})$ amphibian ferritin subunit mRNA.

\section{Single Stranded Regions of the 5'Untranslated Regulatory} Region of Ferritin MRNA

When the results of modification or cleavage were examined under conditions similar to those used for translation or binding of specific ferritin regulatory proteins $\left(40 \mathrm{mM} \mathrm{K}^{+}, \mathrm{pH}=7.2\right)$ (Table 1, Figures $2 \& 3$ ), most of the nucleotides predicted to be in single stranded regions (loops or bulges) were cleaved by RNAase $\mathrm{T}_{1}$ or OPCu. [OpCu cleaves single-stranded regions of tRNA (26).] Single-stranded cutting reagents cleaved at positions $5,7,9,14,15,16,35$, and 45 . In addition, dimethyl sulfate alkylated $A$ at position 13 and $C$ at positions $6,41,47$, and 48 (data not shown), which also are in loops or bulges in the predicted structure. Notable exceptions to the predicted structure are the alkylation of $\mathrm{A}^{21}$ and $\mathrm{A}^{22}$ (not shown) and the cleavage by $\mathrm{OPCu}$ of $\mathrm{U}^{18}$ and $\mathrm{U}^{19}$ at $0.5 \mathrm{mM}$ magnesium. At $5 \mathrm{mM}$ magnesium, no cleavage occurred with $\mathrm{OPCu}$. The results were similar for both $\mathrm{H}$ and $\mathrm{H}^{\prime}(\mathrm{M})$ ferritin subunit mRNAs in natural mixtures. Interestingly, although several of the OPCu cleavage 
sites near bulges or internal loops are $\mathrm{G}$ residues, the sites were not cleaved by RNAase $T_{1}$.

Several residues in the predicted CAGUGU/C hairpin loop had reactivities which indicate specific and magnesium-sensitive conformations. For example, $\mathbf{G}^{\mathbf{1 6}}$ was cleaved poorly, if at all, by RNAase $T_{1}$ whereas $G^{14}$ was cleaved readily (Figure 3 ). Moreover, both residues were less accessible to cleavage by $\mathrm{OPCu}$ in the absence of magnesium, although cleavage occurred readily in $0.5 \mathrm{mM}$ magnesium (Figure 2, lanes 1 and 3). In contrast to native mRNAs, the structure of the in vitro transcript; (IVT), which has a $\mathrm{G} \rightarrow \mathrm{A}$ substitution at position 16 , was much less dependent upon magnesium than the natural mRNAs (data not shown) even when a full length 3 '-untranslated region (UTR) was present; the pseudogene used as a template for the IVTs was 97\% identical to the ferritin M-subunit mRNA (25). OPCu cleavage patterns for the natural ferritin mRNAs and the IVTs were essentially identical in $0.5 \mathrm{mM}$ magnesium. Differences in the magnesium sensitivity of the IRE regulatory region of native ferritin mRNA and the IVT probably relate to the replacement of $\mathrm{G}^{16}$ by $A$ in the hairpin loop of pseudogene transcript; $A^{16}$ was readily modified by DMS. Under the conditions used, structural effects of changing the $3^{\prime}$-UTR were not detected.

\section{Double-stranded Regions}

Large segments of the ferritin $5^{\prime}$-untranslated regulatory region are predicted to be double-stranded. Reagents accessible to openor single-stranded regions confirmed the prediction because of the small number of reactive sites. For example, only 2 of a total of $13 \mathrm{G}$ residues were readily cleaved by RNAase $\mathrm{T} 1$, only 3 of $15 \mathrm{~A}$ and 4 of $20 \mathrm{C}$ residues were highly methylated and only 13 of 73 the nucleotides examined were strong sites for $\mathrm{OPCu}$ cleavage at 0 or $0.5 \mathrm{mM}$ magnesium (Figure 2, lanes $1 \& 3$ ). At $5 \mathrm{mM}$ magnesium apparently no sites are accessible to $\mathrm{OPCu}$ suggesting that a stable secondary structure exists including all predicted bulges and loops.

$\mathrm{V}_{1}$ nuclease cleavage sites were also few in number (Figure 2). However, $V_{1}$-sensitive sites were generally not reactive with single-strand specific reagents. Two exceptions are residues $U^{35}$ and $\mathrm{G}^{36}$ which were cleaved both by OPCu and by $V_{1}$ nuclease. Such discrepancies in the specificity of $V_{1}$ have been observed before, particularly at sharp bends in a helix (27). $V_{1}$ nuclease cleavage patterns were unaffected by magnesium $(0.5 \mathrm{mM})$ (Figure 2) or by increasing the ratio of $V_{1}$ nuclease/RNA.

$A$ region of apparent conformational variation occurs near residue $\mathrm{C}^{6}$ and at the base of the hairpin loop, sequences which are required for iron regulation of ferritin synthesis (17). For example, the computer-predicted structure shows the $\mathrm{G}^{5}-\mathrm{C}^{23}$ pair plus the $U^{7}-A^{22}$ and $U^{8}-A^{21}$ base pairs flanking the $C^{6}$ bulge. However, $A^{21}$ and $A^{22}$ are methylated and $U^{8}$ can be cleaved by $\mathrm{OPCu}$, although $\mathrm{U}^{7}$ is $\mathrm{V}_{1}$ sensitive. Additional magnesium-sensitive variations occur in bases in the predicted pairs $C^{9}-G^{20}, A^{10}$ and $U^{19}$, and $A^{11}$ and $U^{18} . G^{20}$ is accessible to $\mathrm{OPCu}$ in 0 or $0.5 \mathrm{mM}$ magnesium, while $\mathrm{U}^{18}$ and $\mathrm{U}^{19}$ are cleaved by $\mathrm{OPCu}$ only at $0.5 \mathrm{mM}$ magnesium. The stability of the stem-loop predicted for the 28 nucleotide IRE is $-3.7 \mathrm{kcal}$. When the flanking region is included $(-15$ to $1,28-40$; Figure 1), the predicted $\Delta \mathrm{G}^{\circ}=-15.1 \mathrm{kcal} / \mathrm{mole}$; eliminating pairing between $\mathrm{G}^{5}-\mathrm{C}^{23}$ does not change the energy. Eliminating base pairing between $\mathrm{U}^{7}-\mathrm{A}^{22}$ changes $\Delta \mathrm{G}^{\circ}$ to $-13.4 \mathrm{kcal} / \mathrm{mole}$ and to $-11.3 \mathrm{kcal} / \mathrm{mole}$ for the $\mathrm{U}^{8}-\mathrm{A}^{21}$ pair, respectively. Similar effects were predicted when base pairing was eliminated for $\mathrm{A}^{10}-\mathrm{U}^{19}(-12.4 \mathrm{kcal})$ and $\mathrm{A}^{11}-\mathrm{U}^{18}(-14.4 \mathrm{kcal})$. The largest effect on predicted stability occurred when pairing between $\mathrm{C}^{9}-\mathrm{G}^{20}$, in that middle of the stem, was eliminated. Two hairpin loop of similar stability $(-9.9,-8.2 \mathrm{kcal})$ were predicted but with different loop sequences.

\section{DISCUSSION}

Ferritin mRNAs are the first eukaryotic mRNAs for which a conserved, message specific, translational regulatory element has been identified (2); the sequence is in the $5^{\prime}$ noncoding segment. Variable copies of the translational regulatory sequence are repeated in the $3^{\prime}$-noncoding segment of the transferrin receptor mRNA. Both mRNAs, which encode proteins related by their function in iron metabolism, are regulated by cellular iron (e.g. $3,4,8,28,29$ ) and the regulatory sequence is called the IRE. Specific translational regulatory proteins and IRE-binding proteins have recently been purified $(10,11,20)$. Little is known about the structure of ferritin mRNA IRE other than the secondary-structure prediction of a stem/hairpin loop. Understanding the structure of the IRE in ferritin mRNA will provide a model for understanding eukaryotic mRNA structure and function as well as understanding the regulation of iron metabolism.

Characterizing the ferritin IRE in native mRNA was possible because of the abundance of ferritin mRNA in polyA ${ }^{+}$RNA

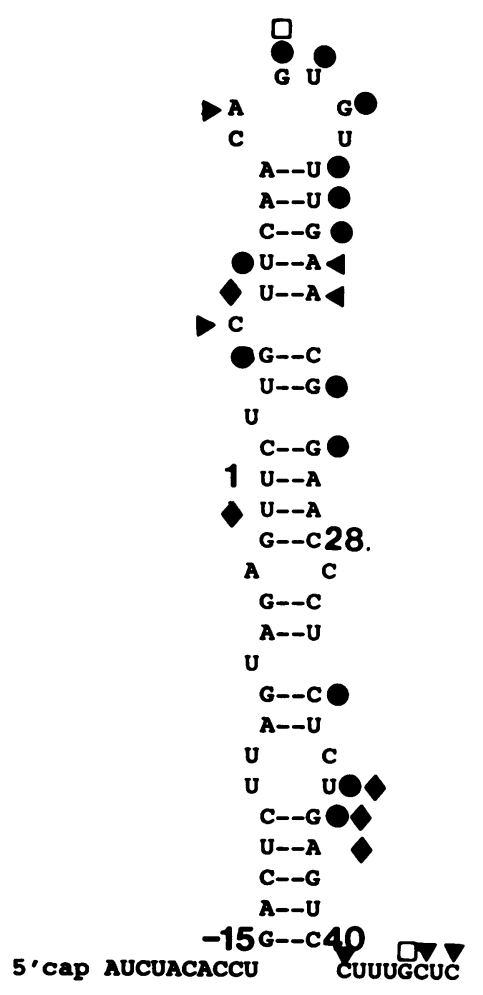

Figure 1. Structure of the Regulatory Region in the 5'-Noncoding Segment of Ferritin mRNA (Bullfrog H Subunit). The predicted secondary structure of the conserved regulatory sequence (IRE) of ferritin mRNAs is shown with paired flanking sequences. The IRE is numbered 1-28 beginning at the $5^{\prime}$ end. Both $\mathrm{H}$ and $\mathrm{H}^{\prime}(\mathrm{M})$ subunits were examined. Taken together the results indicate a 20 base-pair hairpin loop that involves both the IRE and flanking sequences; stem residues bordering bulges or internal loops show magnesium sensitivity. Residues $\mathrm{G}^{14}, \mathrm{U}^{15}, \mathrm{G}^{16}, \mathrm{U}^{18}$, and $\mathrm{U}^{19}$ are cleaved at $0.5 \mathrm{mM}$ magnesium, but not at 0 or $5 \mathrm{mM}$ magnesium (Figure 2). Major cleavage sites (see Figures 2 and 3) are indicated as follows: RNAase $V_{1}-$; RNAase $T_{1}-\square$; 1,10-phenanthroline$\mathrm{Cu}(\mathrm{OPCu})-\bullet$; sites of dimethyl sulfate alkylation (data not shown) - $\nabla$. 


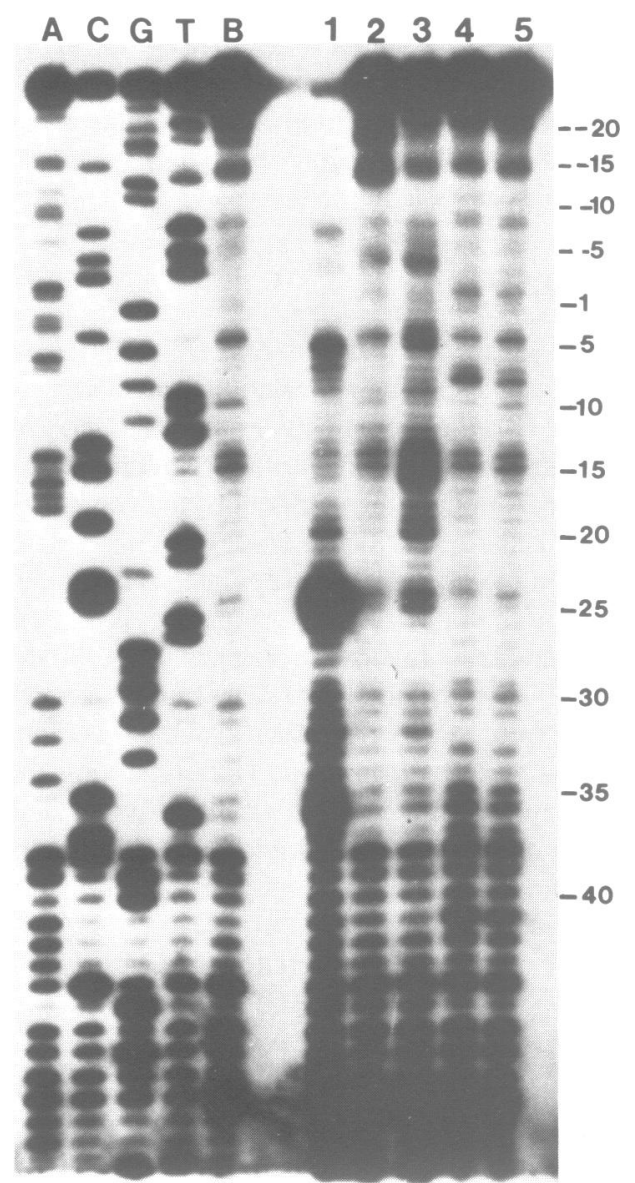

Figure 2. 1,10-Phenanthroline-Cu and RNAase $\mathrm{V}_{1}$ Cleavage of the 5'-Noncoding Regulatory Region of Natural Ferritin mRNA [H Subunit] at various Magnesium Concentrations Analyzed by Primer Extension. Ferritin mRNA in natural polyA+ RNA mixtures from frog red cells was cleaved with chemical or enzymatic nucleases and the cleavage sites determined by primer extension using primers that bound 15-23 nucleotides downstream (depending on the subunit mRNA probed) from the conserved regulatory sequence (IRE) (see Materials and Methods). The IRE is numbered $1-28$ and the base paired flanking regions extend to -15 and to 40 (see Figure 1). ACGT: Reaction mixtures with dideoxynucleotides were used to calibrate the gel. Data for the $\mathrm{H}$ subunit mRNA is presented but similar results were obtained with the $H^{\prime}(\mathrm{M})$ subunit mRNA. B-primer extension of uncleaved $\mathrm{mRNA}$; lanes $1-3 \mathrm{OPCu}$ in $0,5 \mathrm{mM}$ and 0.5 $\mathrm{mM} \mathrm{Mg}$; lanes 4,5 are $\mathrm{V}_{1}$ digestion products in 0 and $0.5 \mathrm{mM} \mathrm{Mg}$. In lane $\mathrm{B}$, the control lane, transcription pause sites can be observed at positions $C^{4}, A^{10}$, $\mathrm{G}^{14}, \mathrm{U}^{15}, \mathrm{G}^{24}, \mathrm{C}^{30}, \mathrm{G}^{38}$, and $\mathrm{U}^{39}$ indicating secondary/tertiary structure in the stem even at $50^{\circ}$ where the reactions were carried out. Cleavage or modification were only scored when the intensity of the autoradiogram was at least three times greater than the control. Note the sensitivity of the OPCu cleavage pattern to $\mathrm{Mg}$; the sensitive sites are in sequences predicted to be at bulges, in internal loops, and around or in the hairpin loops. The results are representative of 3-5 experiments.

from embryonic red cells (3); similar results were obtained with a ribo-oligonucleotide of 55 bases containing the IRE and flanking regions (Harrell and Theil, preliminary observations). The results of cleaving or modifying ferritin mRNA with RNAases $T_{1}$ and $\mathrm{V}_{1}$, dimethyl sulfate and the chemical nuclease 1,10-phenanthroline- $\mathrm{Cu}(\mathrm{OPCu})$ revealed several notable features: (1) The conserved IRE and flanking region combined form a hairpin loop but several magnesium-dependent conformers exist which vary at predicted bulges and the stem of the hairpin loop; (2) Base specific features appear to occur in the hairpin loop; (3) OPCu detected predicted regions of bulges of internal loops which were not sensitive to protein nucleases; (4) The combined secondary structure of the IRE and flanking region is 6 or 10

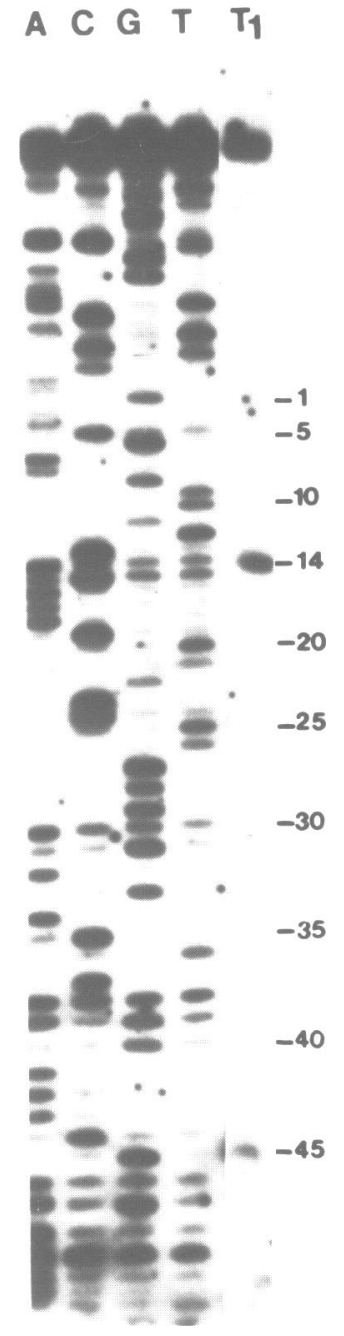

Figure 3. RNAase $T_{1}$ Cleavage of the 5'-Noncoding Regulatory Region of Natural Ferritin mRNA (H Subunits) Analyzed by Primer Extension. Ferritin mRNA in polyA + RNA from frog embryonic red cells was cleaved with RNAase $T_{1}$ and the products examined by primer extension (see Materials and Methods). ACGT-Reaction mixtures with dideoxy nucleotides to calibrate the gel. The conserved regulatory sequence (IRE) is numbered 1-28 and the base-paired flanking region extends to -15 and 40 (see Figure 1). Most of the $G$ residues are predicted to be in the stem. Only $\mathbf{G}$ residues predicted to be in single-stranded regions or in the hairpin loop were cleaved. $\mathbf{G}$ residues near bulged or internal loop regions which were accessible to 1,10-phenanthroline-Cu (Figure 2), were inaccessible to the enzyme. $M g$ had no effect on the RNAase $T_{1}$ cleavage pattern. Note the absence of cleavage of $G^{16}$ in the hairpin loop even though $G^{14}$ is readily cleaved. The results are representative of three experiments.

nucleotides from the cap for the $\mathrm{H}^{\prime}(\mathrm{M})$ and $\mathrm{H}$ ferritin subunit mRNAs, respectively.

\section{The Hairpin}

Conservation of the 28 nucleotides of the ferritin mRNA IRE is so striking that attention has been focused almost entirely on the IRE to the exclusion of the flanking nucleotides (e.g., $13,17,19,22)$. However, both the IRE and flanking regions have extensive secondary structure. For example, only a small fraction of the nucleotides in either the IRE or the 13-14 nucleotides on either side of the IRE were accessible to probes of singlestranded or open RNA, i.e., dimethyl sulfate, RNAase $T_{1}$, and 1,10-phenanthroline-Cu. Such results support the prediction of secondary structure in the IRE and flanking sequences (Figure 
1). However, structural variations occur among residues at the edges of predicted bulges and internal loops. For example, $\mathrm{G}^{24}$, $\mathrm{G}^{25}, \mathrm{U}^{35}, \mathrm{G}^{36}$ are very sensitive to magnesium at physiological concentrations (Figure 2); similar data were obtained for both natural ferritin subunit mRNAs examined [H and $\left.\mathrm{H}^{\prime}(\mathbf{M})\right]$. Deviations in reactivity of the IRE region from the predicted secondary structure occur at $0.5 \mathrm{mM}$ magnesium in the region between $C^{6}$ [required for function (17)] and the hairpin loop, e.g. methylation of $A^{21}$ and $A^{22}$ and OPCu cleavage of $U^{7}, U^{18}$, $\mathrm{U}^{19}$, and $\mathrm{G}^{20}$. Moreover, computer analysis of the effect of eliminating base pairing showed only small effects on predicted stability if the disruption were near the loop or $\geq 3$ base pairs away. Such results suggest that conformational heterogeneity or possibly tertiary interactions may contribute to the regulatory function of the ferritin mRNA IRE region although regulatorprotein binding, measured as altered mobility during electrophoresis, was unchanged by magnesium $(19,22$; Harrell, Walden, and Theil, unpublished observations).

\section{Secondary/Tertiary Structure in the Hairpin Loop}

Several observations show that the hairpin loop has specific structural features. For example, two neighboring $\mathrm{G}$ residues in the IRE, positions 14 and 16, have different reactivities to RNAase $T_{1}$. In addition, cleavage of either $G$ by $O P C u$ is dependent on magnesium. When $A$ is substituted for $G$ at position 16 in the transcript of the $\mathrm{H}^{\prime}(\mathrm{M})$ ferritin subunit pseudogene, the site is readily accessible to alkylation by dimethyl sulfate (Table 1). The importance of base sequence and structure in the loop for function is indicated by the observation that substitution of $\mathrm{A}$ for $\mathrm{G}$ at position 16 of an oligodeoxyribonucleotide containing the IRE reduces protein binding in gel-shift assays (29).

\section{Novel Features of Cleavage by 1,10-phenanthroline- $\mathrm{Cu}(\mathrm{OPCu})$}

$\mathrm{OPCu}$ is an attractive probe of structure because of the lack of base specificity (30). An additional feature is the potential of $\mathrm{OPCu}$ to detect structural details too small to be probed by a bulky protein nuclease, as illustrated in Figures 2 and 3. Only two $G$ residues in the ferritin mRNA region examined were cleaved by RNAase $T_{1}$ (Figure 3 ) suggesting that the other eleven in the sequence were in base-paired regions. However, interruptions (bulges or internal loops) are predicted in the stem near seven additional $G$ residues. Although the predicted interruptions in stem structure around the seven $G$ residues were transparent to RNAase $T_{1}$, five of the seven $G$ residues were accessible to OPCU in a magnesium-dependent fashion; $\mathrm{OPCu}$ clearly displayed the interruptions in the base-paired stem. Finally, the independence of reactivity of OPCu on magnesium facilitated the detection of magnesium dependent changes in the hairpin loop and stem structure (Figure 2, lanes 1-3).

\section{Location of the IRE and Paired Flanking Region in Relation the Cap}

Translational regulation of ferritin mRNA involves initiation $(3,7,9,13)$. Both the IRE and specific cell extracts are required for regulation of ferritin mRNA translation $(5,13,15,16)$. The location of the IRE is $16-38$ nucleotides from the cap (2) which could be too far for effects on initiation $(31,32)$. Flanking the conserved sequence are nucleotides which have extensive base pairing (Figure 1). Similar base pairing can be predicted in the eight ferritin mRNAs for which sequence is available $(25,34-38)^{1}$. The length of the predicted stem is proportional to the distance of the IRE from the cap (39). Thus, when the IRE and the flanking regions are combined, the secondary structure is only 8-12 nucleotides from the cap in ferritin mRNA from human, rat, chicken, and frog (see Figure 1), which provides a reasonable explanation for the influence of the IRE regulatory region on translation initiation. Alternatively, the 90 $\mathrm{kDa}$ regulatory protein $(10,11,20,21)$ could simply mask the entire region, but the binding site of the protein is not yet known. How the regulatory protein(s) and excess cellular iron change ferritin mRNA structure to enhance translation and why only secondary structure is conserved in the flanking regions, in contrast to constant primary structure in the IRE, are questions for the future.

\section{ACKNOWLEDGEMENTS}

The authors are grateful to R.A. McKenzie for the RNAase $T_{1}$ cleavage analysis and to Lin Peng-Nian for computer analysis of the effect of base pairing in the IRE stem on predicted stability of the IRE and flanking region stem.

This work was supported in part by Grant DK20251 (to E.C.T.) from the National Institutes of Health. The computer resources used were provided by the BIONET National Computer Resource for Molecular Biology, part of whose funding is provided by the Biomedical Research Technology Program, Division of Research Resources, National Institutes of Health Grant 1 U41 RR-01685-02; later the University of Wisconsin Genetics Computer Group Programs were used on a local network. This is a contribution from the Department of Biochemistry, College of Agriculture and Life Sciences and College of Physical and Mathematical Sciences and is Paper No. 11984 of the Journal Series of the North Carolina Agricultural Research Service, Raleigh, NC 27695-7643. The costs of publication of this article were defrayed in part by the payment of page charges. This article must therefore be hereby marked 'advertisement' in accordance with 18 U.S.C. Section 1734 solely to indicate this fact. A preliminary account of the work was presented at the joint meeting of the American Society for Cell Biology and the American Society for Biochemistry and Molecular Biology, January 30-February 2, 1989.

\section{REFERENCES}

1. Theil, E.C. (1987) in Translational Regulation of Gene Expression (Ilan, J., ed.), Plenum Press, New York, 141-163; Ann. Rev. Biochem. 56, 289-315

2. Theil, E.C. (1990) J. Biol. Chem. 265, $4771-4774$

3. Shull, G.E. and Theil, E.C. (1982) J. Biol. Chem. 257, 14187-1419

4. Shull, G.E. and Theil, E.C. (1983) J. Biol. Chem. 258, 7921-7923.

5. Aziz, N. and Munro, H.N. (1986) Nucleic Acids Res. 14, 915-927

6. Didsbury, J.R., Theil, E.C., Kaufman, R.E. and Dickey, L.F. (1986) J. Biol. Chem. 261, 949-955

7. Schaefer, F.V. and Theil, E.C. (1981) J. Biol. Chem. 256, 1711-1715

8. Zahringer, J., Baliga, B.S. and Munro, H.N. (1976) Proc. Natl. Acad. Sci. U.S.A. 73, 857-861

9. Dickey, L.F., Wang, Y.-H., Shull, G.E., Wortman, I.A. III and Theil, E.C. (1988) J. Biol. Chem. 263, 3071-3074

\footnotetext{
'After submission of the manuscript, a note appeared (39) presenting the sequence of a liver ferritin cDNA from adult Xenopus in which the distance from the IRE to the cloning site was 157 nucleotides and the length of the sequence between the apparent initiator AUG and the cloning site was 200 nucleotides longer than any other known ferritin mRNA 5'untranslated region (5'UTR). In addition, in contrast to other known ferritin mRNAs, the Xenopus sequence encoded an open reading frame within the extra 200 nucleotides. Whether the cDNA clone represents a minor species of ferritin mRNA heretofore undetected or is characteristic of all Xenopus ferritin mRNA awaits the future analysis of the RNA
} 
10. Brown, P.H., Daniels-McQueen, S., Walden, W.E., Patrino, M.M., Gaffield, L., Bielser, D., Bailey, L.C. and Thach, R.E. (1989) J. Biol. Chem. 264, $13383-13386$

11. Walden, W.E., Daniels-McQueen, Brown, P.H., Gaffield, L., Russell, D.A., Biesler, D., Bailey, L.C. and Thach, R.E. (1988) Proc. Natl. Acad. Sci. U.S.A. 85, 9503-9507

12. Spirin, A.S. (1969) Eur. J. Biochem. 10, 20-35

13. Aziz, N. and Munro, H.N. (1987) Proc. Natl. Acad. Sci. U.S.A. 84, 8478-8482

14. Caughman, S.W., Hentze, M., Rouault, T.A., Harford, J.B. and Klausner, R.D. (1988) J. Biol Chem. 263, 19048-19052

15. Hentze, M.W., Rouault, T.A., Caughman, S.W., Dancis, A., Harford, J.B. and Klausner, R.D. (1987a) Proc. Natl. Acad. Sci. U.S.A. 84, 6730-6734

16. Hentze, M.W., Caughman, S.W., Rouault, T.A., Barriocanal, J.G., Dancis, A., Harford, J.B. and Klausner, R.D. (1987b) Science 238, 1570-1573

17. Hentze, M.W., Caughman, S.W., Casey, J.L., Koeller, D.M., Rouault, T.A., Harford, J.B. and Klausner, R.D. (1988) Gene 72, 201-208

18. Rouault, T.A., Hentze, M.W., Dancis, A., Caughman, W., Harford, J.B. and Klausner, R.D. (1987) Proc. Natl. Acad. Sci. U.S.A. 84, 6335-6339

19. Rouault, T.A., Hentze, M.W., Caughman, S.W., Harford, J.B. and Klausner, R.D. (1988) Science 241, 1207-1210

20. Rouault, T.A., Hentze, M.W., Haile, D.J. and Harford, J.B. (1989) Proc. Natl. Acad. Sci. USA 86, 5768-5772

21. Walden, W.E., Patino, M.M. and Gaffield, L. (1989) J. Biol. Chem. 264, $13765-13769$

22 .Leibold, E.A. and Munro, H.N. (1988) Proc. Natl. Acad. Sci. U.S.A. 85, 2171-2175

23. Zucker, M. and Stiegler, P. (1981) Nucleic Acids Res. 9, 133-148

24. Yoon, C., Kuwabara, M.D., Law, R., Wall, R. and Sigman, D.S. (1988) J. Biol. Chem. 263, 8458-8463

25. Dickey, L.F., Sreedharan, S., Theil, E.C., Didsbury, J.R., Wang, Y.-H. and Kaufman, R.E. (1987) J. Biol. Chem. 262, 7901-7907

26. Murakawa, M.D., Chen, C.B., Nierlich, D.P. and Sigman, D.S. (1989) Nucleic Acids Res. 17, 5393-5395

27. Lowman, H.B. and Draper, D.E. (1986) J. Biol. Chem. 261, 5396-5403

28. Müllner, E.W. and Kühn, L.C. (1988) Cell 53, 615-825

29. Koeller, D.M., Casey, J.L., Hentze, M.W., Gerhardt, E.M., Chan, L.N., Klausner, R.D. and Harford, J.B. (1989) Proc. Natl. Acad. Sci. USA 28, 3574-3578

30. Sigman, D.S. (1986) Accounts Chemical Res. 19, 180-186

31. Pelletier, J. and Sonenberg, N. (1985) Cell 40, 515-526

32. Lawson, T.G., Ray, B.K., Dodds, J.P., Grifo, J.A., Abramson, R.D., Merrick, W.C., Botsch, D.F., Weith, H.L. and Thach, R.E. (1986) J. Biol. Chem. 261, 13979-13989

33. Inoue, T. and Cech, T. (1985) Proc. Natl. Acad. Sci. U.S.A. 82, 648-652

34. Stevens, P.W., Dodgson, J.B., and Engel, D.G. (1987) Mol. Cell. Biol. 7, $1751-1758$

35. Aziz, N., and Munro, H.N. (1987) Proc. Natl. Acad. Sci. U.S.A. 84, $8478-8482$

36. Hentze, M.W., Rouault, T.A., Caughman, S.W., Dancis, A., Harford, B., and Klausner, R.D. (1987) Proc. Acad. Sci. U.S.A. 84, 6739-6734

37. Hentze, M.W., Caughman, S.W., Casey, J.L., Koeller, D.M., Rouault, T.A., Harford, J.B., and Klausner, R.D. (1988) Gene 72, 201-208

38. Walden, W.E., Patino, M.M., and Gaffield, L. (1989) J. Biol. Chem. 264, 13765-13769.

39. Moskaites, J.E., Pastori, R.L. and Schoenberg, D.R. (1990) Nucleic Acids Research 18:2814.

40. Frier, S.M., Kierzek, P., Jaeger, J.A., Sugimoto, N., Caruthers, M.H., Neilson, T. and Turner, D.H. (1986) Proc. Nat. Acad. Sci. 83:9373-9377. 